\title{
La evolución de la
}

cultura política china: una aproximación a través del modelo teórico de Almond y Verba* / The evolution of the Chinese political culture: an approximation through the theoretical model of Almond and Verba

* Recibido: 9 de febrero de 2014. Aceptado: 14 de marzo de 2014. Tla-Melaua, revista de Ciencias Sociales. Facultad de Derecho y Ciencias Sociales. Benemérita Universidad Autónoma de Puebla, México / issN: 1870-6916 / Nueva Época, Año 9, No 38, abril / septiembre 2015, pp. 6-23. 
Este trabajo consiste en un análisis de las relaciones entre cultura y política en la historia de China. Realizamos un estudio de la evolución de la cultura política siguiendo el modelo teórico de Almond y Verba. Identificamos así tres fases fundamentales en dicha evolución: una primera cultura política parroquial-súbdita, que corresponde a la China imperial tradicional; una segunda cultura política súbdita, que corresponde a la China de Mao, y una tercera súbdito-participativa, que corresponde a la China actual post Mao. Concluimos apuntando hacia la probabilidad de que en un futuro próximo la cultura política de China sea de tipo participativo y fomente la aparición de una nueva cultura cívica en el país.

PALABRAS CLAVE

Cultura política, China, confucionismo, maoísmo, participación.
This essay entails an analysis of the relationship between culture and politics in the history of China. We performed a study of the evolution of the political culture in China following the theoretical model of Almond and Verba. We identify three fundamental phases in this evolution: first, a parochial-subject political culture that corresponds to the traditional Imperial China; second, a subject political culture that corresponds to the China of Mao; and third, a citizenparticipatory political culture that corresponds to the current Post-Mao China. We conclude pointing out the probability that in a near future the political culture in China will be of a participatory kind and will promote the emergence of a new civic culture in the country.

KEYWORDS

Political culture, China, Confucionism, Maoism, participation.

\footnotetext{
*Doctoranda en Ciencia Política, Universidad Complutense de Madrid, España. (liyinzho@ucm.es)
} 

según Almond y Verba / 3. La cultura política de China / 4. Conclusión

\section{INTRODUCCIÓN}

La cultura y la política tienen una relación inherentemente estrecha. La idea de la cultura como variable para explicar los fenómenos políticos se puede remontar a la época de la antigua Grecia. Muchos grandes pensadores occidentales han hecho grandes aportaciones en esta área, como Platón, Aristóteles, Montesquieu, Tocqueville, Weber, entre otros. En el siglo Xx, la cultura política como una aproximación independiente de investigación se popularizó gracias a la publicación del libro The Civic Culture. Political Attitudes and Democracy in Five Nations, ${ }^{1}$ de Gabriel A. Almond y Sidney Verba, en 1963. Durante más de medio siglo, este enfoque recibió muchas críticas. ${ }^{2}$ Sin embargo, en el área de la investigación de la cultura política, los académicos han llegado al consenso de que la aproximación de cultura política tiene autonomía en el análisis político, especialmente después de la publicación de El Renacimiento de Cultura Política, de Ronald F. Inglehart, en 1988.

En este trabajo vamos a estudiar la evolución de la cultura política china, siguiendo el modelo teórico de Almond y Verba.

\footnotetext{
${ }^{1}$ En 1956, Almond y Verba acuñaron el concepto de "cultura política" en su tesis llamada "Comparative Political Systems" publicada en Fournal of Politics, vol. 18, pp. 391-409. En 1963, en su libro, siguieron explicando: "Hablamos de 'cultura política' de una nación antes que de 'carácter nacional' o 'personalidad formal', y de 'socialización política', antes que del desarrollo o educación infantil en términos generales. No elegimos estos términos porque rechacemos las teorías psicológicas y antropológicas que relacionan las actitudes políticas con otros componentes de la personalidad, o porque no admitamos las teorías que subrayan la relación existente entre el desarrollo del niño en términos generales y la inducción del niño hacia sus roles y actitudes políticas del adulto".

${ }^{2}$ Para el enfoque "Elección Racional", la maximización de los intereses es el factor más explicativo en el análisis político. Por eso no hace falta considerar los factores como valores, sentimientos o cognición. Los marxistas occidentales también creen que los valores políticos cambian según la transformación de la estructura socio-económica, mientras que los comportamientos políticos, actitudes políticas y la estructura política provienen de la estructura de clases. Por eso, degradaron al enfoque como una "categoría residual" y lo empujaron al margen de la ciencia política.
} 


\section{El MARCO teórico de la CULtura POLÍtica según ALMOND Y VERBA}

El estudio de la cultura política de Almond y Verba es clásico en esta área. En su opinión, "la cultura política de una nación consiste en la particular distribución entre sus miembros de las pautas de orientación hacia los objetos políticos". 3

T. Parsons y E. Shills clasifican los tipos de orientación política que forman la cultura política. Ésta incluiría orientaciones cognitivas, como el conocimiento y las creencias; afectivas, como los sentimientos, y evaluativas, como los juicios.

Los objetos políticos hacia los que se dirigen las orientaciones de los individuos son básicamente cuatro: el sistema político como objeto general, los objetos políticos (inputs), los objetos administrativos (outputs) y el propio sujeto considerado como objeto político.

Por eso, caracterizar la cultura política de una nación significa analizar las diferentes especies de orientaciones cognitivas, afectivas y evaluativas hacia el sistema político en general, sus aspectos políticos y administrativos y la propia persona como miembro activo de la política. "Esta clasificación de las culturas políticas es la más relevante y resulta plenamente operativa actualmente". ${ }^{4}$

La conocida clasificación de los tres "tipos ideales" de cultura política son: la parroquial, la de súbdito y la participante. En la cultura de tipo parroquial o localista no hay una conciencia clara de la mayoría de los aspectos del sistema político, ni de cómo son los procesos políticos o del gobierno.

Se da en sociedades atrasadas, así como en sociedades desarrolladas entre los campesinos habitantes de zonas remotas, entre la población analfabeta, es decir, en gente que ignora la política y desconoce el impacto de las decisiones políticas sobre sus vidas. La encontramos como forma dominante en los sistemas de tipo tradicional y tribal. ${ }^{6}$

En la cultura de tipo súbdito "el ciudadano es consciente del sistema político, pero se limita a obedecer pasivamente a las leyes y a los agentes públicos, no vota ni se involucra en la actividad política". ${ }^{7}$ Los súbditos tienden a acudir en la ayuda del gobierno en lugar de transmitirle sus reivindicaciones. Las sociedades de este tipo de cultura política suelen ser regímenes autoritarios.

En la cultura de tipo participativo, "el ciudadano es consciente y participa activamente en el proceso político, está informado, formula demandas y apoya

\footnotetext{
${ }^{3}$ Gabriel A. Almond y Sydney Verba, "La cultura política", en Diez Textos Básicos de Ciencia Política, Ariel, Madrid, 1996, p. 180.

${ }^{4}$ Manuel Sánchez de Dios, Política Comparada, Madrid, Síntesis, 2012, p. 79.

${ }_{5}^{5}$ Almond y Verba, "La cultura política", en Diez Textos Básicos de Ciencia Política, Ariel, Madrid, 1996, p. 184.

${ }^{6}$ Manuel Sánchez de Dios, Política Comparada, Madrid, Síntesis, 2012, p. 79.

${ }^{7}$ Ibid.
} 
con su voto a los líderes políticos. Es la propia de los sistemas democráticos, está vinculada al desarrollo del capital social". 8

Sin embargo, la congruencia entre cultura y sus estructuras políticas recién mencionada no es absoluta. Almond dice que todas culturas políticas "reales" se entienden como híbridas que presentan siempre elementos de los tres tipos en proporciones dispares. "Utilizamos el término de culturas políticas sistemáticamente mixtas para referirnos a aquellas en que hay proporciones importantes de orientación". "'Las culturas políticas pueden permanecer sistemáticamente mixtas durante mucho tiempo, $[\ldots]$ cuando permanecen mixtas, existen roces inevitables entre cultura política y estructura, y una tendencia característica a la inevitabilidad estructural". ${ }^{10}$ En este sentido, podemos distinguir tres tipos de culturas políticas sistemáticamente mixtas, según Almond: 1) la cultura parroquial-súbdita; 2) la cultura súbdita-participante, y 3) la cultura parroquial-participante.

La cultura parroquial-súbdita se trata de un tipo de cultura política en que una parte sustancial de la población ha rechazado las pretensiones exclusivas de una difusa autoridad tribal, rural o feudal y ha desarrollado una lealtad hacia un sistema político más complejo, con estructuras de gobiernos centrales especializadas. ${ }^{11}$

En la cultura mixta de súbdito y participación, una parte sustancial de la población ha adquirido orientaciones políticas (inputs) especializadas y un conjunto activo de auto-orientaciones, mientras que la mayor parte del resto de la población continúa orientada hacia una estructura gubernamental autoritaria y posee un conjunto relativamente pasivo de auto-orientaciones. ${ }^{12}$

En la cultura parroquial-participante nos encontramos con el problema del desarrollo cultural en muchas naciones incipientes. En estos países, la cultura política es predominantemente parroquial, pero se han introducido las normas estructurales de ser participantes. "La cultura mixta de súbdito y participación es el problema más conocido, e incluso más actual. El paso positivo de una cultura de súbdito a otra de participación abarca la difusión de orientaciones positivas hacia una infraestructura democrática, la aceptación de normas de obligación cívica y el desarrollo de un sentido de competencia cívica en una proporción sustancial de la población". ${ }^{13}$

\footnotetext{
${ }^{8}$ Ibid.

${ }^{9}$ Almond, Gabriel y Verba, Sídney, "La cultura política”, op. cit., p. 187.

${ }^{10} \mathrm{Ibid}$.

${ }^{11}$ Ibid, p. 188.

${ }^{12}$ Ibid, p. 189.

${ }^{13}$ Almond, Gabriel y Verba, Sídney, "La cultura política", op. cit., p. 191.
} 
Concretamente, entre todos los sistemas políticos mezclados de los tres tipos, en los países desarrollados y democráticos hay más de $60 \%{ }^{14}$ de la población que podría encuadrarse en el grupo de los que tiene una cultura participativa, mientras que $30 \%$ tiene cultura de tipo súbdito y $10 \%$ tiene cultura de tipo parroquial. En los regímenes autoritarios domina, por el contrario, una cultura política de súbdito. En los sistemas políticos de base tradicional en sociedades preindustriales, más de $60 \%$ tiene una cultura parroquial.

La cultura política es la muestra de la cultura cívica en la vida política. El tema nuclear de la teoría de la cultura cívica de Almond consiste en "qué tipo de cultura política favorece la estabilidad de la democracia". Después de analizar las culturas políticas de Italia, México, Alemania, Estados Unidos e Inglaterra, llegó a la conclusión de que la cultura cívica, "entendida como una cultura pluralista, basada en la comunicación y en la persuasión, en el consenso y en la diversidad; una cultura que permite el cambio pero que, sobre todo, lo modera", ${ }^{15}$ es el resultado de los conflictos entre la modernización y el tradicionalismo.

La cultura cívica es una cultura política equilibrada y de los participantes. La cultura política participativa es su mejor expresión. Lo más importante de la democracia es la cultura cívica, es decir, la participación, porque, a través de ella, los ciudadanos elevan su nivel de conciencia de la política e influyen de forma acumulativa en el proceso de toma de decisiones. Para los países en vías de desarrollo, la socialización política a través de la educación y los medios de comunicación puede implantar los elementos componentes de la cultura cívica a los ciudadanos, con el objetivo de aumentar su nivel de participación política.

\section{La CULTURA POLÍtica DE China}

La cultura política de China se formó en la época imperial. Durante miles de años de desarrollo estable, en la cultura política tradicional se organizó un sistema estable de valores que se dispersó en todos los terrenos de la vida social y política. Enraizada en las ideas, la conciencia y la psique de la población china, la cultura política tradicional, basada fundamentalmente en las enseñanzas de Confucio, valiéndose de todos los canales culturales y sociales, se transmitió de generación en generación.

Con el desarrollo de la historia, en las postrimerías del siglo xIx, la estructura económico-política de la sociedad china y su forma de gobernanza experimentaron unas revoluciones enormes. Cada revolución significó el esta-

\footnotetext{
${ }^{14}$ Sánchez de Dios, Manuel, Política Comparada, Madrid, Síntesis, 2012.

${ }^{15}$ María Luz Morán, "Los estudios de cultura política en España”, Reis, núm. 5, pp. 97-130, eneromarzo, 1999, p. 101.
} 
blecimiento de un nuevo tipo de sistema político de valores; en consecuencia, los valores interiores de la cultura política también cambiaron. Cada cambio también se depositó en la psique del pueblo chino y se transmitió hasta nuestros días. Con miras a entender la cultura política de China actual, es preciso hacer una retrospectiva de la trayectoria de su desarrollo e influencias.

\subsection{La cultura política tradicional china: cultura política parroquial-súbdita}

La cultura política china viene de sus modos tradicionales de producción y de la vida de la gente. En la sociedad feudal de China, dominaba la economía de pequeños campesinos con base en el sistema de la propiedad privada de tierra. Por un lado, los campesinos agrupados en unidades económicas familiares cultivaban en libertad sus parcelas de tierra; por otro, se veían sometidos al dominio del poder estatal. Esta estructura económica era la característica fundamental de la sociedad feudal china y también formaba parte de la base profunda y firme para la edificación y la larga existencia de todas las superestructuras feudales, como su política y su cultura. A dicha economía de pequeños campesinos en sí le faltaba la fuerza de cohesión social y así se necesitaba la fuerza externa administrativa; por tanto, se formó un enorme sistema de burocracia con el absolutismo monárquico como núcleo.

La base principal era el sistema de la familia, con el cual se mantenían los lazos de la sociedad antigua china. De acuerdo con ello, se distinguía la condición de clase y se decidía la herencia de la propiedad y del poder. La familia se consideraba como la base del Estado, y éste, la extensión de aquélla. El emperador no sólo era el gobernante en la política, sino el padre supremo de todo el país. Estos son los elementos fundamentales de la estructura social de la China feudal, lo cual nos ofrece la llave para conocer la cultura política tradicional china. Las características sintetizadas son las siguientes:

a. Dar importancia a Guanxi. El confucianismo considera al individuo como un elemento para constituir la sociedad; así, el valor del individuo se realiza en la red personal de la sociedad. Por lo tanto, es importante formar parte de una red de Guanxi. En algún sentido, este tipo de relación privada influye directamente en la elevación de la posición política. El motivo para desarrollar Guanxi es obtener la seguridad y realizar los intereses propios. Por eso, depender de la autoridad es el mejor método para tener seguridad.

b. Estimar el orden y confiar en el colectivo. En la cultura política tradicional china, la psicología política de los chinos, que trata de la necesidad del orden y dependencia del colectivo, se produce una situación en la cual los chinos prefieren intentar mantener aparentemente un consenso a destruir la harmonía. Porque en el colectivo y la vida ordenada se alcanzarían mejor las 
metas. En la sociedad china, se subraya que el individuo debe sacrificar sus propios intereses frente a los intereses colectivos cuando éstos van a dañarse. Así se reprime la expresión de las necesidades individuales, incluyendo sus demandas políticas.

c. Obedecer a la autoridad. Los chinos tienden a obedecer a la autoridad, considerando que bajo la autoridad se puede garantizar el orden y la necesidad colectiva. Durante el proceso de socialización de los niños chinos, se someten a la educación de la ética tradicional y se les exige obedecer al poder parental. La consecuencia de esta obediencia se convierte en el apoyo de la base de la autoridad monárquica cuando la autoridad familiar se expande a toda la sociedad.

d. Complejo de funcionario "padre-madre" y funcionario honesto e integro. Los chinos tienen un sentimiento específico al tratar a los personajes políticos como a los padres. En la familia, respetar la autoridad de los padres es la ética fundamental, lo cual se convierte en la obediencia a la autoridad política cuando los gobernantes muestran su posición como la autoridad de la ética. Así, los chinos tienden a obedecer fácilmente no a un individuo sino al régimen. La sociedad antigua de China abogaba por la gobernanza con la ética. Esta tradición es la raíz de la situación actual, en la cual el sistema político chino presta más atención a la gobernanza según los personajes políticos que a la gobernanza según la ley.

Debido a la cultura tradicional arriba mencionada, los ciudadanos chinos desarrollaron una conciencia política muy pasiva, que dificulta el desarrollo de la cultura cívica en la sociedad contemporánea. Pero la dependencia hacia la autoridad no es incondicional; la autoridad debe ser moral. Lucian Pye indicó que los chinos creen que tener moralidad significa poseer el poder de gobernar, e incluso la moralidad, la volición de los gobernantes, tiene una proporción directa con la eficiencia de gobernanza. ${ }^{16}$ Si el gobernante no actúa con moralidad, las masas van a buscar otra persona que corresponda con la condición de ser desinteresado. Esta exigencia ocasiona la falta de grupos de interés y la ausencia del mecanismo y la conciencia de competición en la política china. ${ }^{17}$

Las amplias masas campesinas, reducidas a su labor agrícola, sin conciencia de la maquinaria imperial estatal, generalmente analfabetas, mantendrían la cultura política de tipo parroquial, propia de las sociedades feudales tradicionales.

\footnotetext{
${ }^{16}$ Lucian W. Pye, China: An Introduction, Little, Brown, 1984, p. 142.

${ }^{17}$ Yingkui, Zhang, La Cultura Política Tradicional China y su Valor Moderno: Tomando la Investigación de Lucian Pye como el Centro, Central Compilation \& Translation Press, Beijing, 2009, p. 65.
} 
Junto a las amplias masas campesinas, la introducción del confucianismo dio forma, desde la dinastía Han (206 a. C-220 d. C.), a un sector de la ciudadanía con vocación de funcionario al servicio de la maquinaria estatal. Se trata de una clase burocrática que en la China imperial se formó con los estudiosos que habían logrado superar los muy difíciles exámenes para el funcionariado del Imperio desde que el séptimo emperador de la dinastía Han Wu Di los instauró. Hasta el fin de la dinastía Qing, hasta 1905, durante más de mil años, este sistema creó una casta burocrática (que se conoció en las últimas dinastías como mandarines). Este sector de ciudadanos, más consciente de la maquinaria estatal y que participaban en su vida política sin cuestionar la autoridad, dio forma en la era tradicional a una cierta cultura política súbdita, que, sin embargo, no era mayoritaria, dado que la mayoría de la población era aún campesina y estaba al margen de la política.

Podemos, por tanto, definir la cultura política de la China tradicional como cultura política parroquial-súbdita. Esta cultura política, como hemos dicho antes, sólo se quebraba cuando el gobernante carecía de moral y no era, por tanto, adecuado para gobernar según la doctrina de Confucio. Entonces, el pueblo se sublevaba y una dinastía era remplazada por otra, dando lugar, tras los breves periodos de rebelión, a una nueva fase imperial caracterizada por la cultura política parroquial-súbdita.

Vamos a analizar ahora los factores que impulsaron el cambio en esta cultura política parroquial-súbdita. Ésta mantuvo el gobierno de la sociedad feudal durante más de 2000 años, hasta que la fuerza externa lo rompió con la guerra del Opio, en 1840. Desde allí, la cultura política tradicional china experimentó tres fases de transformación. La primera fase fue de los últimos cincuenta años de la dinastía Qing. En general, se concentró en usar algunos elementos de la cultura política occidental como herramienta para mejorar la estructura del dominio, con el fin de reducir el conflicto entre el pueblo y el gobierno feudal.

La segunda fase comenzó desde la Revolución de 1911 (también conocido como la Revolución de Xinhai o Revolución de Hsinhai), con la cual se desmoronó la dinastía imperial y se destruyó la base económica de pequeños campesinos. Esta fase se conoce como la antigua democracia. El líder Sun Yat-sen fundó el primer partido moderno chino y diseñó el primer sistema de la cultura política moderna de China. Este sistema tomó los tres principios del pueblo como núcleo: el nacionalismo, la democracia y el bienestar popular.

La tercera fase fue desde el movimiento de 4 de mayo de 1919, hasta el establecimiento de la China socialista de 1949. Dicho movimiento estudiantil marcó el inicio de la revolución de nueva democracia. En consecuencia, se planteó el Movimiento de Nueva Cultura, basado en las teorías de la cultura política del Occidente moderno: abogaba por la libertad, la igualdad y la 
democracia. Durante este movimiento cultural se negó completamente la cultura política tradicional; indicaron que la cultura confuciana tradicional y su ideología política impidieron el proceso de modernización de China.

La transformación de la cultura política de la China contemporánea no es el resultado de su propio crecimiento, sino que se realizó su cambio pasivamente frente a su inadaptabilidad al desarrollo de la sociedad moderna, especialmente de cara a los continuos fracasos en su competición con la cultura occidental. Sin embargo, el cambio de la cultura política en la primera mitad del siglo pasado desmoronó el sistema del gobierno feudal de más de 2000 años y su raíz cultural, lo cual estableció la base para el desarrollo próximo con la divulgación de los conceptos de la democracia, libertad e igualdad en los intelectuales y funcionarios chinos.

Esta nueva cultura no consiguió enraizar en las personas comunes por falta de base fundamental. Por ejemplo, no había una economía de mercado para formar una clase media ni una fuerte sociedad cívica. Los grupos de clase burocrática y el autoritarismo de aquel entonces obstaculizaron el engendramiento de la cultura democrática. Por lo tanto, la transformación de la cultura política tradicional de China adoptó una actitud muy pasiva. Sólo con estímulos externos se experimentó paulatinamente su cambio. Por otro lado, para la cultura política tradicional china es muy difícil realizar un cambio radical de forma activa, puesto que la China antigua tenía un defecto de institución fundamental en su estructura de la economía, la política y la sociedad. Esto imposibilitó el crecimiento de la cultura política moderna.

Con la llegada de Mao Zedong, se superó la cultura política de tipo parroquial y se consolidó una cultura política súbdita, pero no se alcanzó todavía la cultura política participante propia de la cultura cívica de sociedades modernas democráticas.

\subsection{La cultura política de la China maoísta: cultura política súbdita}

El 1 de octubre de 1949, Mao proclamó en Beijing la República Popular de China. Mao, inspirándose en el modelo de Partido Leninista, e influido por la experiencia de la Unión Soviética, dio forma a un Partido-Estado de tipo autoritario que se convirtió en una poderosa maquinaria política, con su propio Ejército: el Ejército Popular de Liberación. La República Popular suponía el fin de la China imperial y la liberación de la población de sus estructuras tradicionales y feudales de dominación. Se repartieron las tierras de cultivo y la propiedad entre los campesinos que antes eran capitalizadas por una minoría de terratenientes. Mao se inspiró en el pensamiento marxista occidental para buscar la liberación del pueblo, pero su voluntad de diseño absoluta del conjunto de la vida política, social, económica y cultural de China impidió el desarrollo de una cultura política participativa. 
Se basó en un modelo socialista de planificación central (basada en planes quinquenales), influido por el leninismo, que tenía su elemento fundamental en las comunas campesinas, a diferencia de la URSS, que promovió las fábricas urbanas y el sector obrero. También existían, aunque de forma minoritaria, en las ciudades, estructuras de industrias públicas con un sistema colectivista y de seguridad social conocido como danwei (unidad de trabajo). Se estableció una autoridad central frente a la auto-organización de la ciudadanía. Su mayor diseño de planificación central, social y económica, que buscaba la rápida industrialización de China. El Gran Salto Adelante (1958-1961) provocó la muerte por hambruna de entre 20 y 30 millones de personas.

Durante su gobierno, Mao eliminó la disidencia y entre uno y dos millones de campesinos fueron ejecutados por contrarrevolucionarios. En el ocaso de su poder, oscurecido por el fracaso del Gran Salto Adelante, lanzó la Revolución Cultural, que duró de 1966 hasta su muerte en 1976. Se buscó reforzar su liderazgo político, luchar contra el revisionismo y eliminar a sus oponentes. Este periodo supuso también un cierre de la cultura política libre y participativa de los ciudadanos. Los ciudadanos vieron en Mao a un nuevo padre, una especie de nuevo emperador, casi un nuevo dios, ante cuyas decisiones sólo se podía obedecer. Como en la película Vivir de Zhang Yimou, los intelectuales considerados progresistas ya no rinden culto al cielo y la tierra (símbolos de la naturaleza en el taoísmo y budismo) o a los padres (símbolos muy importantes confucianismo), sino a la figura de Mao.

La cultura política en la era de Mao puede calificarse como súbdita. Aunque supuso un avance frente a la cultura política parroquial-súbdita de la China imperial, la mayoría de la población ajena al mundo político estaba sometida al arbitrio de un poder feudal, mientras una casta de mandarines hacía funcionar una máquina estatal. La China de Mao sustituyó a los mandarines por los oficiales públicos, con lo que la estructura burocrática tampoco cambió sustancialmente.

Mao se apoyó siempre en una concepción militante de las masas. La revolución vendría para él de las masas campesinas, a las cuales movilizó desde el comienzo con popularidad, repartiendo la tierra propiedad de los campesinos ricos. Por ello, llevó a cabo masivos proyectos de educación de la conciencia socialista en las masas campesinas, mediante sus dispositivos de adoctrinamiento y propaganda. La población de China creció en la época de Mao espectacularmente: de 500000 a 900 000. Muchas regiones vivían prácticamente en aislamiento, dedicadas a sus tareas campesinas sin conciencia política alguna.

Podemos decir que la cultura política parroquial todavía existía en muchas partes del país. Sin embargo, la tendencia general desde la constitución del Partido Comunista de China y la guerra civil contra el Kuomintang y la guerra contra los invasores japoneses, fue la creación de una sociedad 
colectivista donde todos estuvieran implicados en la construcción socialista del país, pero sin participación democrática real. La cultura política dominante era por tanto la cultura política súbdita: se acataban las leyes y las directrices centrales sin cuestionar el poder en ningún caso. Pero esta cultura política evolucionó hacia nuevas formas participantes tras la desaparición de Mao y la llegada del nuevo líder, Deng Xiaoping.

\subsection{La cultura politica de la China post Mao: cultura política súbdito-participativa hacia una cultura política participativa}

Desde 1978, con la llegada de Deng Xiaoping al poder, se abrió una nueva etapa de reformas y cambios en China. La estructura colectivista de comunas es desmantelada y los campesinos empiezan a convertirse en pequeños productores privados. La estructura urbana de la danwei (unidad de trabajo) en las empresas estatales sigue existiendo, pero se reduce cada vez más y se permite progresivamente la libertad de empresa y el sector privado. Tras el éxito en los años ochenta de los experimentos capitalistas en las zonas económicas especiales, sobre todo del sur de China, surge el llamado socialismo con características chinas, que desarrollaron posteriormente los líderes Jiang Zemin, Hu Jintao y ahora Xi Jinping.

Es una estructura híbrida que combina el Partido-Estado de tipo leninista con un creciente sector de economía libre privada. Los controles gubernamentales de la población también se relejan y se amplían progresivamente las libertades, pero siempre dentro del orden fijado por el Partido-Estado y sin participación democrática. Los individuos dejan de estar vinculados con los planes centrales colectivistas y se convierten en entes autónomos, en una creciente economía de mercado basada en la competencia. El modelo impulsado por Deng fue un éxito: más de 200 millones de personas dejaron la pobreza y se formó una nueva clase media con más de 300 millones de personas.

Las nuevas tecnologías de comunicación, especialmente internet y las redes sociales, en este clima de crecientes libertades, impulsaron la emergencia de una incipiente sociedad civil, basada en individuos autónomos que exigen participar en los asuntos políticos para mejorar sus condiciones de vida. Pero el interés principal de la mayoría de la gente seguirá siendo la economía y la mejora material, sin involucrarse en cuestiones políticas. Por lo tanto, junto a la estructura todavía no de democracia participativa, capitalizada por el Partido-Estado, hace que la cultura política de la era post Mao sea de tipo súbdito-participativo; es decir, que combina la cultura política de la era maoísta anterior con una nueva tendencia a la participación. En el futuro, a corto o medio plazo, si las líneas reformistas siguen, será posible que se forme una cultura política participativa, porque en China ya hay un embrión de ella. 
Para analizar el clima de la cultura política de China actual, tomamos como referencia el marco teórico establecido por Almond y Verba. En concreto, se analizan las orientaciones cognitivas, afectivas y evaluativas de la cultura política de los chinos en esta época. Para medir sus conocimientos, creencias, sentimientos y juicios sobre la democracia, vamos a continuación a utilizar los datos de World Values Survey (wvs) durante la $5^{\mathrm{a}}(2005-2009)$ y $6^{\mathrm{a}}$ (2010-2014) ola; en nuestro caso, encuestas realizadas en China en 2007 y en 2012, ${ }^{18}$ que fueron consultadas en este banco de datos el 20 de agosto de 2014.

\begin{tabular}{|c|c|c|c|c|}
\hline \multicolumn{5}{|c|}{ World Values Survey ( Ola 5ª: 2005-2009; Ola 6ª 2010-2014) } \\
\hline \multicolumn{5}{|c|}{ 1. Sistema político: tener un sistema político democrático } \\
\hline & \multicolumn{2}{|c|}{ Base=1991, año 2007} & \multicolumn{2}{|c|}{ Base $=2300$, año 2012} \\
\hline Resultado & $\begin{array}{l}\text { Número } \\
\text { de casos }\end{array}$ & $\% /$ Total & $\begin{array}{l}\text { Número } \\
\text { de casos }\end{array}$ & $\% /$ Total \\
\hline Muy bueno & 449 & 22.6 & 613 & 26.7 \\
\hline Bastante bueno & 767 & 38.5 & 1007 & 43.8 \\
\hline Bastante malo & 59 & 3 & 131 & 5.7 \\
\hline Muy malo & 17 & 0.8 & 33 & 1.4 \\
\hline No responde & 4 & 0.2 & 125 & 5.4 \\
\hline No sabe & 696 & 34.9 & 391 & 17 \\
\hline Número de casos & 1991 & 100 & 2300 & 100 \\
\hline
\end{tabular}

\begin{tabular}{|l|l|l|l|l|}
\hline & \multicolumn{2}{|l|}{ Base=1991, año 2007 } & \multicolumn{2}{l|}{ Base=2300, año 2012 } \\
\hline $\begin{array}{l}\text { Base=1991; } \\
\text { Weighted results }\end{array}$ & $\begin{array}{l}\text { Número } \\
\text { de casos }\end{array}$ & \%/Total & $\begin{array}{l}\text { Número } \\
\text { de casos }\end{array}$ & \%/Total \\
\hline Not at all important & 16 & 0.8 & 16 & 0.8 \\
\hline 2 & & & 8 & 0.4 \\
\hline 3 & 6 & 0.3 & 13 & 0.6 \\
\hline 4 & 12 & 0.6 & 17 & 0.7 \\
\hline 5 & 63 & 3.1 & 74 & 3.2 \\
\hline 6 & 147 & 7.4 & 106 & 4.6 \\
\hline 7 & 111 & 5.6 & 281 & 12.2 \\
\hline 8 & 314 & 15.7 & 442 & 19.2 \\
\hline 9 & 275 & 13.8 & 443 & 19.3 \\
\hline Absolutely important & 710 & 35.6 & 689 & 29.9 \\
\hline No answer & 4 & 0.2 & 132 & 5.8 \\
\hline Don't know & 336 & 16.9 & 92 & 4 \\
\hline Número de casos & 1991 & 100 & 2300 & 100 \\
\hline
\end{tabular}

${ }^{18}$ World Values Survey, Data $\&$ Documentation. [Consulta: 20 de agosto, 2014]. Disponible en: http://www.wvsevsdb.com/wvs/WVSAnalizeQuestion.jsp 


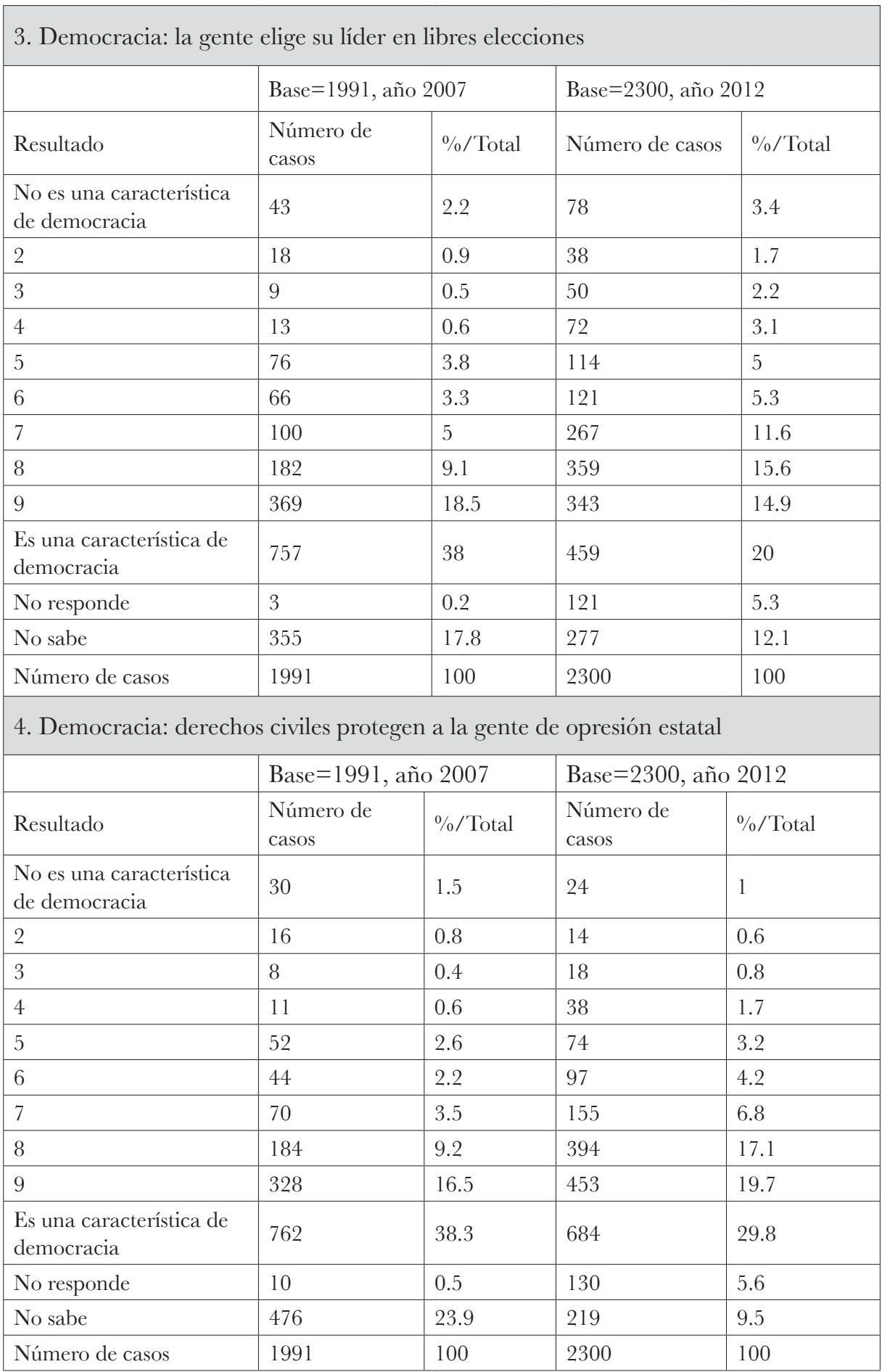

Fuente: Elaboración propia con datos de World Values Survey, Data \& Documentation. [Consulta: 20 de agosto, 2014]. Disponible en: http://www.wvsevsdb.com/wvs/WVSAnalizeQuestion.jsp 
Podemos ver, en esta tabla, sobre la conveniencia de un sistema democrático para un buen gobierno, los encuestados que dicen que es muy bueno o bastante bueno aumentan de $61.1 \%$ en 2007 a 70.5\% en 2012 (pregunta 1). Sobre la importancia de la democracia (pregunta 2), aumentan de $70.7 \%$ en 2007 a 80.6\% en 2012. En cuanto a la función de la democracia, la mayor importancia está en elegir los líderes por elecciones y en garantizar derechos civiles frente a la opresión (pregunta 4 y 5). Casi 70.6\% (en 2007) y 62.1\% (en 2012) de los encuestados tienen tendencia a considerar que "la gente elige su líder en libres elecciones" es característica esencial de una democracia. Casi $67.5 \%$ (en 2007) y 73.4\% (en 2012) de los encuestados tienen tendencia a considerar que "los derechos civiles protegen a la gente de la opresión estatal" es característica esencial de una democracia. ${ }^{19}$ De estos aspectos, podemos deducir que los chinos han desarrollado la conciencia política democrática.

\begin{tabular}{|c|c|c|c|c|}
\hline \multicolumn{5}{|c|}{ 5. Importancia de la política en la vida } \\
\hline \multirow[b]{2}{*}{ Resultado } & \multicolumn{2}{|c|}{ Base $=1991$, año 2007} & \multicolumn{2}{|c|}{ Base $=2300$, año 2012} \\
\hline & $\begin{array}{l}\text { Número } \\
\text { de casos }\end{array}$ & $\% /$ Total & $\begin{array}{l}\text { Número } \\
\text { de casos }\end{array}$ & $\% /$ Total \\
\hline Muy importante & 264 & 13.3 & 239 & 10.4 \\
\hline Bastante importante & 695 & 34.9 & 651 & 28.3 \\
\hline No muy importante & 558 & 28 & 1.07 & 46.5 \\
\hline No importante & 111 & 5.6 & 165 & 7.2 \\
\hline No responde & 9 & 0.4 & 20 & 0.9 \\
\hline No sabe & 354 & 17.8 & 155 & 6.8 \\
\hline Número de casos & 1991 & 100 & 2300 & 100 \\
\hline \multicolumn{5}{|c|}{ 6. Estar interesado en la política } \\
\hline & \multicolumn{2}{|c|}{ Base $=1991$, año 2007} & \multicolumn{2}{|c|}{ Base $=2300$, año 2012} \\
\hline Resultado & $\begin{array}{l}\text { Número de } \\
\text { casos }\end{array}$ & $\% /$ Total & Número de casos & $\% /$ Total \\
\hline Muy interesado & 561 & 28.2 & 247 & 10.8 \\
\hline algo interesado & 671 & 33.7 & 799 & 34.7 \\
\hline No muy interesado & 397 & 19.9 & 743 & 32.3 \\
\hline No interesado & 195 & 9.8 & 466 & 20.2 \\
\hline No responde & 6 & 0.3 & 45 & 2 \\
\hline No sabe & 162 & 8.1 & - & - \\
\hline Número de casos & 1991 & 100 & 2300 & 100 \\
\hline
\end{tabular}

Fuente: Elaboración propia con datos de World Values Survey, Data \& Documentation. [Consulta: 20 de agosto, 2014]. Disponible en: http://www.wvsevsdb.com/wvs/WVSAnalizeQuestion.jsp

${ }^{19}$ Considerando que los grados 7, 8, 9 tienden a la afirmación de "es una característica de democracia", el porcentaje en el texto representa la suma de los tres. Se ha hecho lo mismo con las siguientes preguntas. 
La quita y la sexta pregunta miden la importancia de la política en la vida diaria y el interés por los asuntos políticos de los chinos. Podemos anotar una disminución en estos dos aspectos, de 48.2\% en 2007 a 38.7\% en 2012, al evaluar la importancia de la política, y de $61.9 \%$ en 2007 a $45.55 \%$ en 2012 , al mostrar su interés. En general, el resultado es positivo para nuestro estudio. La razón sería la siguiente: el cambio del contexto político-económico en los últimos veinte años en China. Primero, a la represión de las manifestaciones de la plaza de Tiananmen, en 1989, sucedió un clima de mucho distanciamiento de la política por miedo a represiones. Este legado histórico, en cierto modo, influye todavía a los mayores que mantengan cierta alerta ante los asuntos políticos. Por otro lado, el desarrollo vertiginoso de la economía china facilita que más gente, sea mayor o sea joven, sean ricos o nuevos ricos, acceda al consumo. El consumismo prevalece en China, que ha distraído la atención de la política al consumo.

Pese a esto, podemos ver los comportamientos que reflejan la cultura política de los chinos actuales: 19.6\% de los 143 encuestados en 2012 (pregunta 7) dice que últimamente han participado una vez en manifestaciones pacíficas; $1.8 \%$ de ellos, dos veces. Esta pregunta no la contestó ninguno en 2007. En cuanto a la participación en boicots (pregunta 8), 50.5\% dice que nunca van a participar, en 2007; en 2012, sólo 9\% dice que nunca. En cambio, 30.6\% dice que han participado más que una vez. Estos comportamientos políticos participativos son muestras del cambio de una cultura política súbita a una cultura política participativa-cívica.

7. Acción política: últimamente ha participado en manifestaciones pacíficas

\begin{tabular}{|c|c|c|c|c|c|}
\hline & \multicolumn{3}{|c|}{ Base $=1991$, año 2007} & \multicolumn{2}{|c|}{ Base $=142$, año 2012} \\
\hline Resultado & \multicolumn{2}{|c|}{ Número de casos } & $\% /$ Total & $\begin{array}{l}\text { Número } \\
\text { de casos }\end{array}$ & $\% /$ Total \\
\hline Nunca & \multicolumn{2}{|l|}{-} & - & 12 & 8.6 \\
\hline Una vez & \multicolumn{2}{|l|}{-} & - & 28 & 19.6 \\
\hline Dos veces & \multicolumn{2}{|l|}{-} & - & 3 & 1.8 \\
\hline No responde & \multicolumn{2}{|l|}{1991} & 100 & 99 & 70 \\
\hline Número de casos & \multicolumn{2}{|l|}{1991} & 100 & 142 & 100 \\
\hline \multicolumn{6}{|c|}{ 8. Acción política: si últimamente ha participado en boicots } \\
\hline & \multicolumn{2}{|c|}{ Base $=1991$, año 2007} & \multicolumn{3}{|c|}{ Base $=164$, año 2012} \\
\hline Resultado & $\begin{array}{l}\text { Número de } \\
\text { casos }\end{array}$ & $\% /$ Total & Resultado & $\begin{array}{l}\text { Número } \\
\text { de casos }\end{array}$ & $\% /$ Total \\
\hline Ha hecho & 67 & 3.4 & Nunca & 15 & 9 \\
\hline Tal vez lo haría & 870 & 43.7 & Una vez & 33 & 19.9 \\
\hline Nunca & 1.005 & 50.5 & Dos veces & 12 & 7.6 \\
\hline
\end{tabular}




\begin{tabular}{|l|l|l|l|l|l|}
\hline No responde & 16 & 0.8 & Tres veces & 1 & 0.6 \\
\hline No sabe & 34 & 1.7 & $\begin{array}{l}\text { Más de tres } \\
\text { veces }\end{array}$ & 4 & 2.5 \\
\hline Número de casos & 1.991 & 100 & No responde & 99 & 60.5 \\
\hline & & $\begin{array}{l}\text { Número de } \\
\text { casos }\end{array}$ & 164 & 100 \\
\hline
\end{tabular}

Fuente: Elaboración propia con datos de World Values Survey, Data \& Documentation. [Consulta: 20 de agosto, 2014]. Disponible en: http://www.wvsevsdb.com/wvs/WVSAnalizeQuestion.jsp

Analizamos que las causas de dicho cambio vienen de la disminución de la represión en el gobierno de $\mathrm{Hu}$ Jintao, respecto a los gobiernos anteriores de Deng Xiaoping y Jiang Zemin. En el mandato de Xi Jinping, junto al desarrollo de los nuevos medios de comunicación que permiten que la información fluya más rápido y llegue desde el exterior y convoque a más trabajadores maltratados e indignados contra la corrupción, mala gestión pública, sin poder ser totalmente controlada por el gobierno, la conciencia cívica y política democrática de los ciudadanos aún aumenta más. La cultura política de la era post Mao se está transformando de tipo súbdito-participativo a más participativo que súbdito.

\section{CONCLUSIÓN}

Como hemos visto en este trabajo, la cultura política de China se explica fundamentalmente por más de 2000 años de confucianismo y régimen imperial que favorecieron la creación de una cultura política en una masa campesina muy servil y ajena a la política, sometida a los arbitrios de los poderes feudales. Una cultura política de tipo parroquial, según la tipología de Almond y Verba. Sin embargo, el énfasis del confucianismo y del estudio para dar forma a un ciudadano ético y moral hizo que se formara un sector de estudiosos de las leyes y del sistema político y legal que tenían conciencia del sistema político, pero que no lo cuestionaban.

Mediante el sistema de exámenes imperiales, surgieron estos funcionarios. Por eso tenemos que calificar la cultura política de la China imperial hasta el fin de la dinastía Qing, a comienzos del siglo xx, como cultura política parroquial-súbdita, según el modelo de Almond y Verba. La cultura súbdita sería la de ciudadanos que conocen el sistema político y acatan sus leyes, para servir al gobierno autoritario en lugar de las reivindicaciones de la ciudadanía contrarias al gobierno.

Con la crisis de la dinastía Qing, y la llegada del movimiento republicano y el movimiento del 4 de mayo, se introdujeron ideas occidentales en China; se piensa que el confucianismo y el sistema imperial tradicional son los 
culpables del retraso de China y de la imposibilidad de su modernización. En este contexto, Mao y el Partido Comunista Chino llegan al poder y fundan la República Popular China en 1949. La cultura parroquial de la era feudal y tradicional imperial es eliminada. Se fomenta una cultura política súbdita en todo el país, de ciudadanos sometidos en un sistema de planificación central basado en comunas campesinas y danweis urbanos. Todas las masas son movilizadas y acatan el orden del Partido; Mao pasa a ser casi divinizado y su autoridad no es cuestionada. Los fracasos del Gran Salto Adelante y de la Revolución Cultural harán que su autoridad absoluta sea puesta en cuestión tras su fallecimiento, en 1976.

Con la llegada al poder de Deng Xiaoping, en 1978, comienza una era de reformas y apertura. Se introduce el "socialismo con características chinas" que combina un régimen político autoritario y de Partido único con crecientes libertades de mercado y economía privada. Esta apertura, unida a los avances tecnológicos en los medios de comunicación y el desarrollo de redes sociales en los últimos años, como Weibo, hará que una parte de la población china empiece a desarrollar una cultura cívica de tipo participante. Como hemos visto, los datos estadísticos del World Values Survey así lo indican. En la era actual la cultura política es súbdita-participativa; aunque existe esa minoría de ciudadanos cada vez más participativos, la mayoría sólo tiene interés en los asuntos materiales y no cuestiona la autoridad política ni reivindica más libertades políticas. En cualquier caso, esta nueva cultura política emergente participativa, aunque todavía combinada con la súbdita, es un fenómeno nuevo en miles de años de cultura parroquial o súbdita de los chinos, y apunta, tal vez, a un futuro en que sea dominante, si el ritmo de crecimiento económico y las reformas progresivas introducidas por los gobernantes no se detienen. 